\title{
The gathering storm
}

\section{Hurricane Katrina, which struck New Orleans last year, has thrust the link between climate change and extreme weather events onto the US political agenda.}

TTar he hurricane season officially opens today in the United States, although the aftershocks from last August's Hurricane Katrina have yet to die down. The breached levees of New Orleans have been repaired, and the government has stockpiled food and water for a million potential storm refugees, but the political structures that mismanaged Katrina remain disturbingly intact.

The now-notorious Federal Emergency Management Agency (FEMA) remains unconvincingly appended to the dysfunctional Department of Homeland Security. And the voters of New Orleans, many still scattered across the country, managed last month to re-elect Mayor Ray Nagin, the individual most closely associated with the city's woeful failure to prepare itself for the storm.

Bad as Katrina was for the city, it could have been even worse. Max Mayfield, director of the National Hurricane Center, points out that New Orleans itself experienced only the winds of a category- 1 hurricane. Yet more than 1,500 Louisianans died, in a flooding disaster that had been predicted for decades. Before Katrina struck, several opportunities for science to properly inform public policy were missed. Afterwards, many asked how a disaster that had been so precisely foreseen could have been allowed to happen.

But can science help now? Can it be integrated into the extraordinary task of rebuilding, planning and growing an entire coast? The answer remains distressingly unclear.

This summer, several assessments of the episode are being released. A group of engineers funded by the National Science Foundation has just issued its final draft report on why the protective levees surrounding New Orleans failed (see page 556 ). It goes beyond technical assessment and has harsh words for the organizational breakdowns that led to the Katrina disaster.

Also forthcoming is a report from the US Army Corps of Engineers, which built the waterworks of southern Louisiana. Another is expected from the state's Team Louisiana, led by Ivor van Heerden of Louisiana State University, a hurricane specialist who pre-Katrina served as the loudest Cassandra of all. It is to be hoped that these evaluations will be digested and acted on by those responsible for the reconstruction of New Orleans.
Another contentious issue brought to the fore by Katrina is the question of whether climate change is making hurricanes worse. In the past year, an emerging consensus has suggested that rising sea surface temperatures may well be causing hurricanes to become more intense over time (see page 564).

It can be debated how significant this effect is: will a few degrees of warming cause enough increase in intensity to ruin people's lives? After all, it is the trajectory of a hurricane that most crucially determines how many people suffer. Yet computer models suggest that the rise in intensity will be sufficient to cause concern.

Hurricane experts must take care not to overplay this link. The public is prone to misunderstanding subtle climate connections. Many people are more likely to recall dramatic scare stories about the possible connection than they are scientists' careful caveats that no particular storm can be attributed to global warming.

More worryingly, the science of hurricanes and global warming seems to be falling into the same trap that has ensnared climate-change research for two
"As US agencies prepare to respond to this summer's hurricanes, science hasan opportunity to improve the lives of millions of people." decades. Researchers are lining up into distressingly familiar camps, with some arguing for the link between tropical storms and climate change, and some against it. They duel at press conferences and snipe at each other on the Internet and in the literature, each side trying to dissect the other's data.

Scientists who have little or no background in hurricanes are suddenly publishing papers in tropical meteorology, sometimes apparently pursuing an agenda. But the community of real hurricane experts is extraordinarily small and doesn't need to be artificially enlarged by people looking to prove a particular point.

As US federal and state agencies prepare to respond to this summer's hurricanes, science has an opportunity to inform and improve the lives of millions of people. Researchers must do their best to ensure that the data, and not the politics, determine the shape of these preparations.

\section{Finding fraud in China}

\section{As Chinese research expands, who is looking out for faked results?}

7 he investigation of research misconduct is always fraught with difficulty, even if the necessary protocols and experienced expert committees are fully in place. In China, they are not. If the nation is to get to grips with the problem of misconduct as it becomes a substantial scientific power, that situation has to change.

Chinese research agencies do have structures for investigating misconduct allegations, but in the absence of open discussion and independent press scrutiny, few researchers have much faith in them. The rapid and open exchange of information over the Internet has some potential to fill the void, but it also carries risks (see Nature $441,392-393 ; 2006$ ). It could readily break down into a dangerous game of unregulated accusation and counter-accusation, shedding no light on actual misconduct.

The power of the Internet in identifying scientific fraud was 